\title{
Impact of Changing Weather Conditions on the Disease Pattern on Grapes in Tasgaon Tehsil in Maharashtra, India
}

\author{
Patil Tejashri* and Yardi Kranti
}

\author{
Bharati Vidyapeeth Institute of Environment, Education \& Research (BVIEER), Bharati \\ Vidyapeeth Deemed University, Katraj, Pune, India
}

*Corresponding author

\begin{abstract}
A B S T R A C T
\section{Keywords}

Climatic change, Fungal infestation, Grape yield, Extreme climatic events, GIS technique

Article Info

Accepted: 12 April 2019 Available Online: 10 May 2019

Climate change has emerged as the most serious environmental challenges. It is necessary to evaluate its impacts on climate-vulnerable development sectors, such as agriculture. Human impacts on environment have resulted in altered environmental conditions that influence changes in abundance and diversity of insect pests. In the present study, an attempt was made to determine the impact of changes in the climatic conditions on grape crop in Tasgaon tehsil. Various weather parameters like rainfall, temperature and relative humidity were analyzed in the region. The results show that the most significant climatic factor influencing the development and yield of grapes is temperature and humidity. Data for the period 2008 to 2017 show an increasing trend in temperatures and change in precipitation in the study area. This affected grape yield due to infestation of diseases and uncertain weather events. These climatic variations are responsible for the increase in fungal infestation of grapes, as well as $40 \%$ to $50 \%$ loss of yield because of inferior quality of fruit. Several adaptation strategies may be used to offset the negative impacts of climate change on diseases and crop yields.
\end{abstract}

\section{Introduction}

The agriculture sector is most sensitive to the changing weather because the nature and characteristics of vegetation and agricultural activity in a region. Changes in temperature and precipitation, often lead to outbreaks of pests and fungal disease in crops (Laxmikantha, 2018). Climate change has emerged as the most prominent of global environment issues and there is a need to evaluate its impact on the agriculture (Maoela a. Maebajoa, 2010). Climatic factors significantly influences grapevine development and growth. Certain stages of grapevine development are sensitive to temperature changes. The spatial pattern of temperature within the vineyard affects growth and development of the grapevine. In addition, metrological events have significant influences on the development of grapevine are cold and wet, Decembers, frost and severe winds (Sluys, 2006).

The major constraints in grape cultivation are the difficulties in replacing the varieties after 
plantation (production constraint), high rates of interest on loans (financial constraint), a higher incidence of pests and diseases, high initial investment for setting up the vineyard (cost-related constraint) and the difficulty in meeting quality requirements for export (Patil, 2008). To analyze the impact of climate change on agriculture sector, longterm rainfall and temperature data, are useful for understanding weather trends over a long period of time (Laxmikantha, 2018). The increase temperature, and elevated carbon dioxide concentrations, are expected to magnify pressure on agricultural systems in various ways (Johnson et al., 2013).

Maharashtra is one of the leading grapeproducing states in the country. The area under grapes-cultivation in Maharashtra is around 90 thousand ha. The state produces about 780 thousand tons annually. In 2011$12,110.58$ thousand tons of grapes, valued at Rs 708.55 crores, that were exported, about $82 \%$ was from Maharashtra (National Horticulture Board, Government of India). Maharashtra ranks first in the production of grapes in India followed by Karnataka and Tamil Nadu. Maharashtra (Nashik, Sangli, Ahmednagar, Pune, Satara, Solapur and Osmanabad are the grape-growing districts in the state) produces mainly table grapes (National Horticulture Board, 2001-02). Agriculture is a major economic activity in Sangli. The district is one of the largest grapegrowing regions in Maharashtra (Ghosh Debjit et al., 2017).

\section{Study area}

Tasgaon tehsil in Sangli district lies between $17.03^{\circ} \mathrm{N} 74.6^{\circ} \mathrm{E}$ at an average elevation of 560 meters. It covers an area of $820 \mathrm{~km}^{2}$. Tasgaon is a drought- prone region, receiving an average annual rainfall of only $540.5 \mathrm{~mm}$. The population of Tasgaon tehsil is 2.5 lakhs people (Census 2011).
The main aim of this study the weather trend and its impact on grape crop. And also to Identify and map the diseases related to changing weather conditions in the area

\section{Materials and Methods}

Primary data was collected from the field through questionnaires and interviews with farmers and agriculture officers of the government. Agricultural practices, land- use patterns, irrigation system used by the farmers, diseases and pests data were obtained by a pilot survey and field observations. Survey of India Topsheets of scale 1: 250,000 were used for delineating the basin boundary, preparation of a base map and extracting different thematic layers for analyses was done. These included village locations, agriculture farming areas and physiography. GIS techniques were used for preparation of distribution of rainfall, humidity, temperature, etc. Interpolation techniques like the IDW tool were used to define distribution of weather conditions.

\section{Results and Discussion}

\section{Agricultural data analysis}

Ten year-data on grape cultivation and production in Tasgaon tehsil is shown in the graph in Chart 1. The information was obtained from the Department of Agriculture, Tasgaon tehsil. The graph shows an increasing trend in grape production from 2011-12. However, there was a sharp drop in 2016-17. The reason for increase in production is due to the increase in area that was brought under grape cultivation. In 201112, Tasgaon tehsil had experienced a severe drought most places which resulted in low yields that year. A gap between expected and actual production can be seen. It is also seen that weather factors like high temperatures and heavy rainfall are becoming more 
frequent with adverse impact on grape production. There are also losses at various places along the production to storage chain (Fig. 1-7).

\section{Variations in rainfall, temperature and relative humidity}

Climatic conditions of temperature, humidity and rainfall have a major impact on crop yield, quality of fruit, as well as the incidence of diseases. The variations in rainfall and temperature data for the area were studied. Data has shown a steady rise in average temperature over the period. Annual rainfall data shows that there is an increasing trend (Chart 2). A similar, more pronounced trend is observed with temperature. In the last 10 years, all except three years experienced high rainfall and temperature (Charts 2 and 3). High temperatures affect the various stages of the grape plants growth: budding, flowering, fruit-setting, and maturation. The impact on yield and cropping schedule is severe.

As seen from Chart 3, there is an increasing trend in average temperature, signifying the effect of climate change in the study area. The temperature shows least increment. The linear trends obtained from the data (Chart. 2) there is less increase in rainfall, while the increase in temperature is significant. The rate of growth of the insect population increases with temperature with an increase in temperature of by $2^{\circ} \mathrm{C}$, insects can go through four to five lifecycles in a season (Parvatha Reddy, 2013).

According to the Intergovernmental Panel on Climate Change (IPCC, 2013), the world's average temperature in the twentieth century has increased by $0.07{ }^{\circ} \mathrm{C}$ every ten years. With increase in temperature natural enemies of insects undergoes adverse effects. Increase in temperature alters the phenology of plants. Higher minimum temperatures in temperate regions lead to expansion of the geographical range of insect pests which are currently intolerant to low temperatures (Prasad and Bambawale, 2010). Thus, increasing temperatures can have significant adverse impacts on grapes in Tasgaon tehsil. Crop plants and pests are, directly or indirectly, affected by increase in temperature.

The extent of damage that pests (insect, mites, nematodes, other invertebrates, vertebrates and microbial pests) is directly associated with the rate of their reproduction, development, survival, spread, or altering host defenses and susceptibility. Indirectly, an increase in temperature has effect on the relationships between pests, their environment (Anand Prakash et al., 2015).

The average annual Relative Humidity ratio of the actual amount of water vapor in the atmosphere compared to the saturation amount of water vapor for Tasgaon tehsil showed a declining trend from 2008 to 2017 (Chart 4). This shows that the relative humidity will decrease as temperatures increase.

The broad consensus on the association of fungal disease with relative humidity is that decrease in humidity promotes an increase in temperature, particularly during summer. Nevertheless, there exists considerable uncertainty regarding this conclusion because the dominant physical and ecological processes affecting disease outbreaks are controlled by many other climatic factors but such changes in weather affects the dynamics of insect populations (Karuppaiah and Sujayanad, 2012).

\section{Climate prediction}

The three important climatic parameters for this study are temperature, rainfall and relative humidity. Considering the present trends, projections of rainfall, temperature and relative humidity are made to study the possible future impacts on grapes. 
Each tehsil is shaded according to the volume of yearly average rainfall for Sangli district. Tasgaon tehsil maintained balanced precipitation over the years ranging from 4.10 $\mathrm{mm}$ to $7.81 \mathrm{~mm}$ yearly. The complete analysis of 10 years suggest that mean rainfall for location have increased but certain locations have exhibited increasing pattern in heavy rainfall (greater than $8 \mathrm{~mm}$ ) during the rainy season. The analysis of 10 years shows that yearly average temperature has risen by $0.5^{\circ} \mathrm{C}$ with an estimate increase of $16.55{ }^{\circ} \mathrm{C}$ to $16.60^{\circ} \mathrm{C}$ from 2008 to 2017 .

Above maps illustrate the change in relative humidity in study area. Data shows decrease in values for study area. The yearly average relative humidity values changed from $58.07 \%$ to $55.42 \%$ from 2008 to 2017. Relative humidity is decreased by $2.65 \%$.

Fig.1 Yearly average rainfall of monsoon season 2008 to 2012

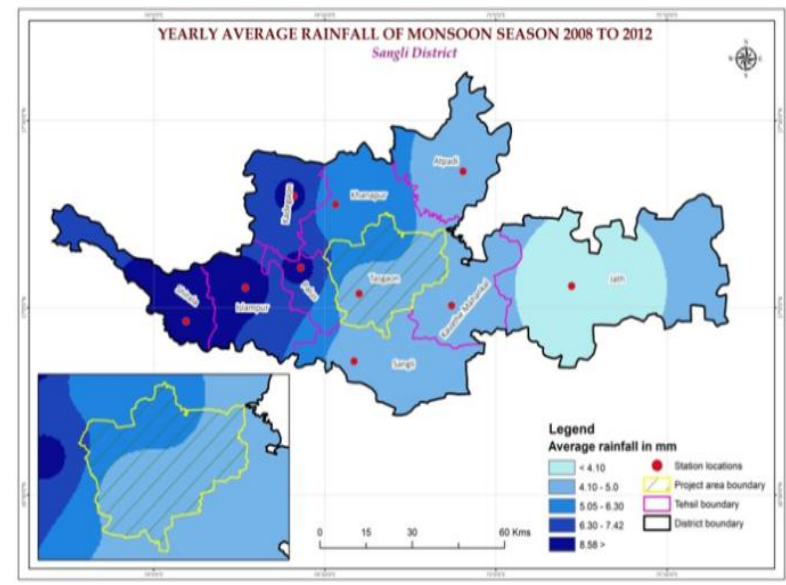

Fig.2 Yearly average rainfall of monsoon season 2013 to 2017

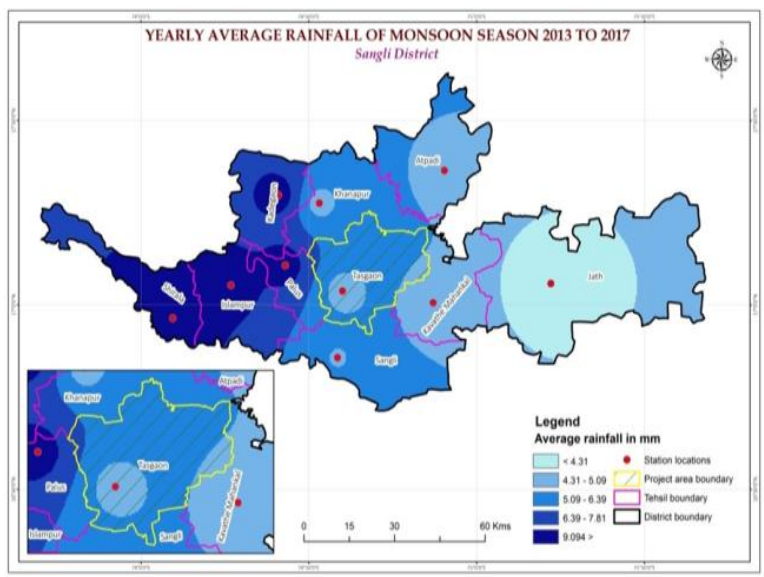


Fig.3 Yearly average temperature of summer season 2008 to 2012

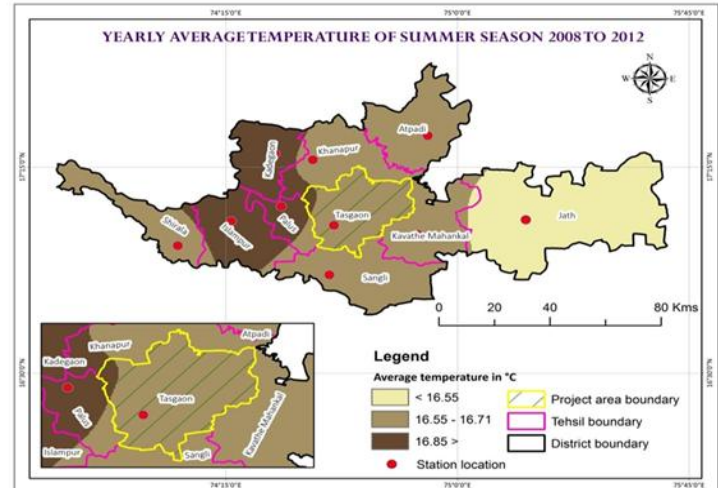

Fig.4 Yearly average temperature of summer season 2013 to 2017

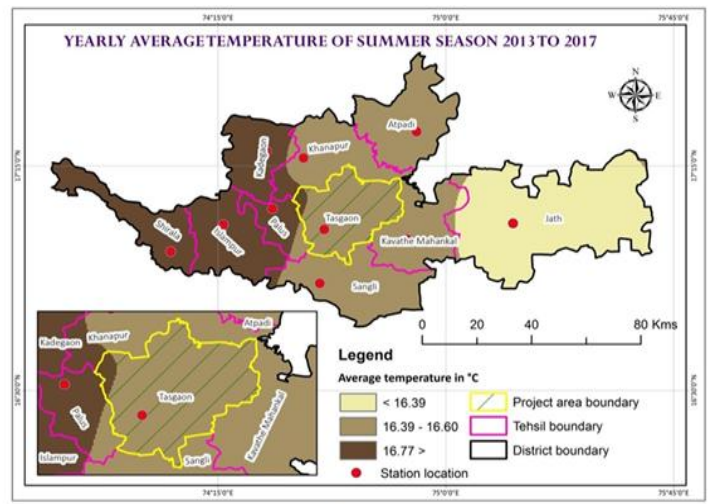

Fig.5 Yearly average relative humidity of winter season 2008 to 2012

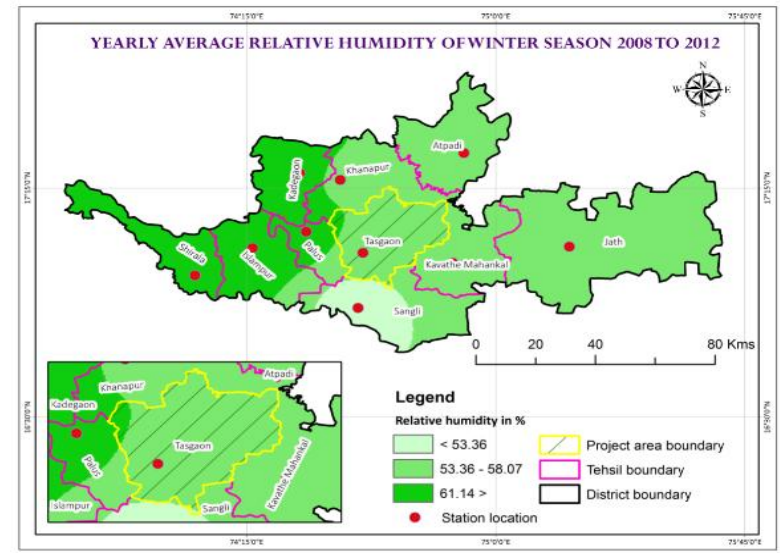


Fig.6 Yearly average relative humidity of winter season 2013 to 2017

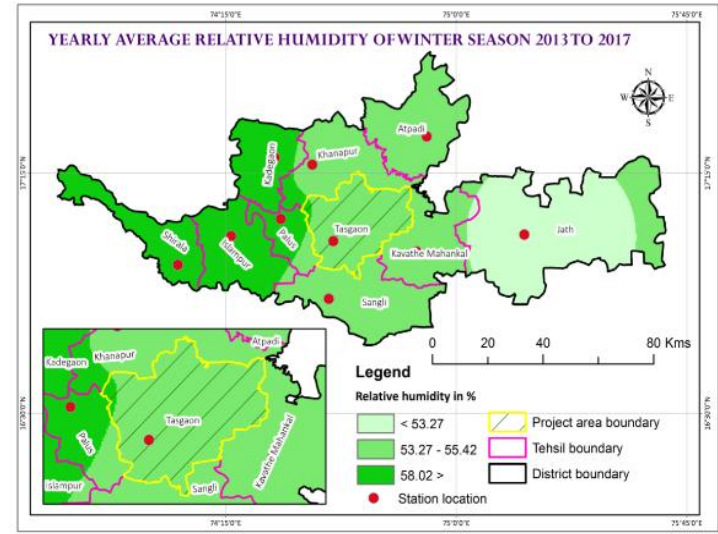

Fig.7 Severity indices of the main grape diseases for selected villages of study area

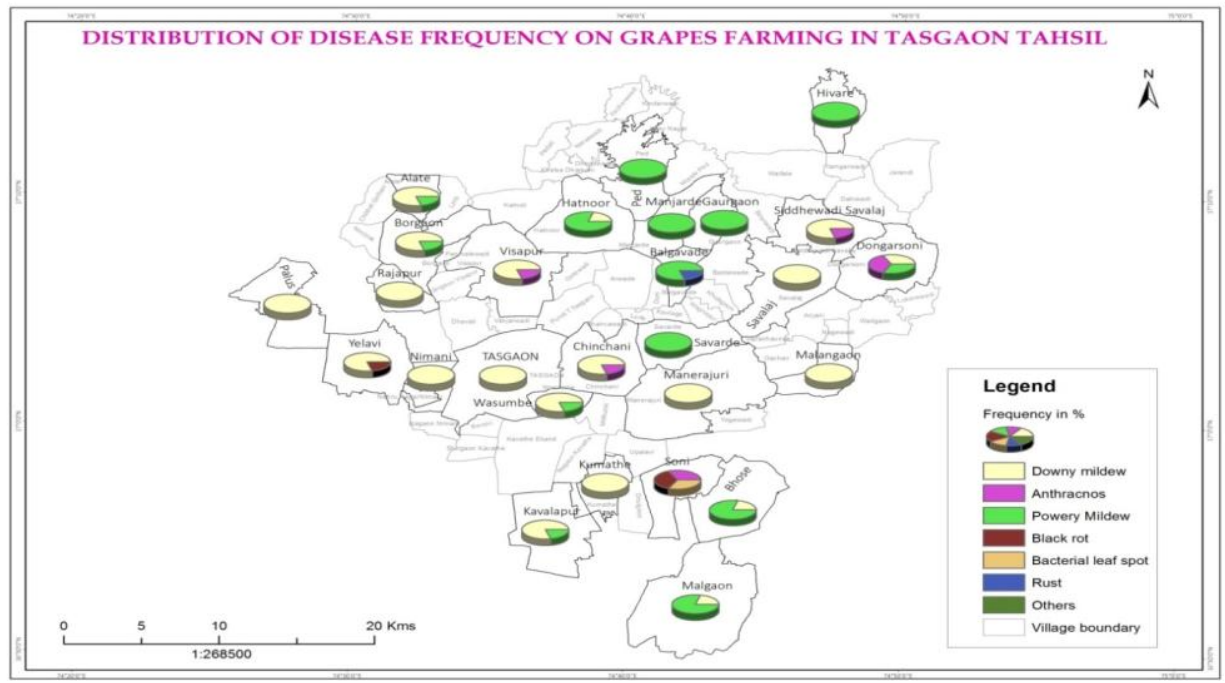

Chart.1 Area under grape cultivation, production and expected yield

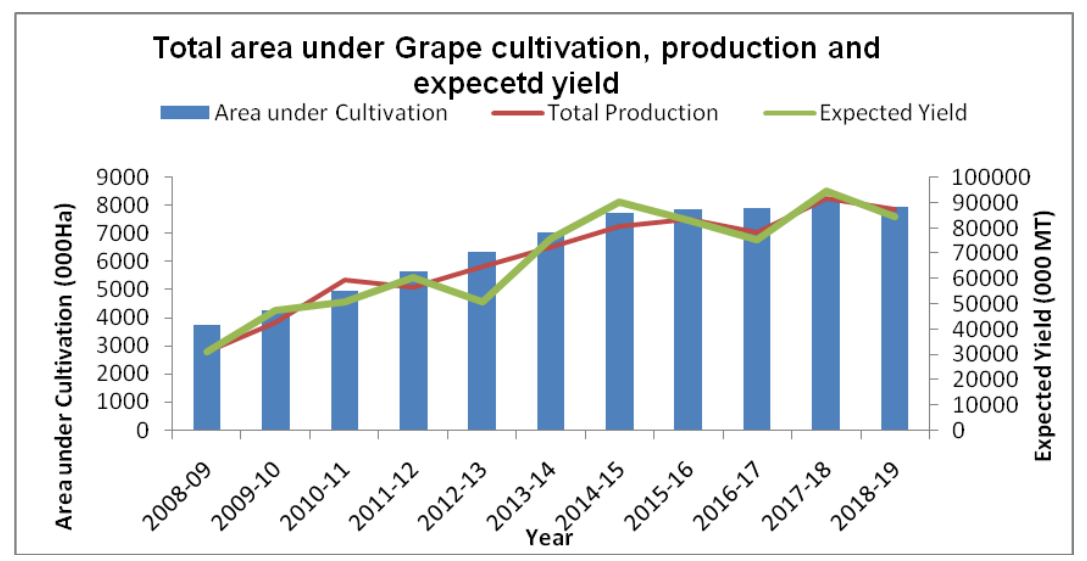


Chart.1 Average annual rainfall from 2008 to 2017

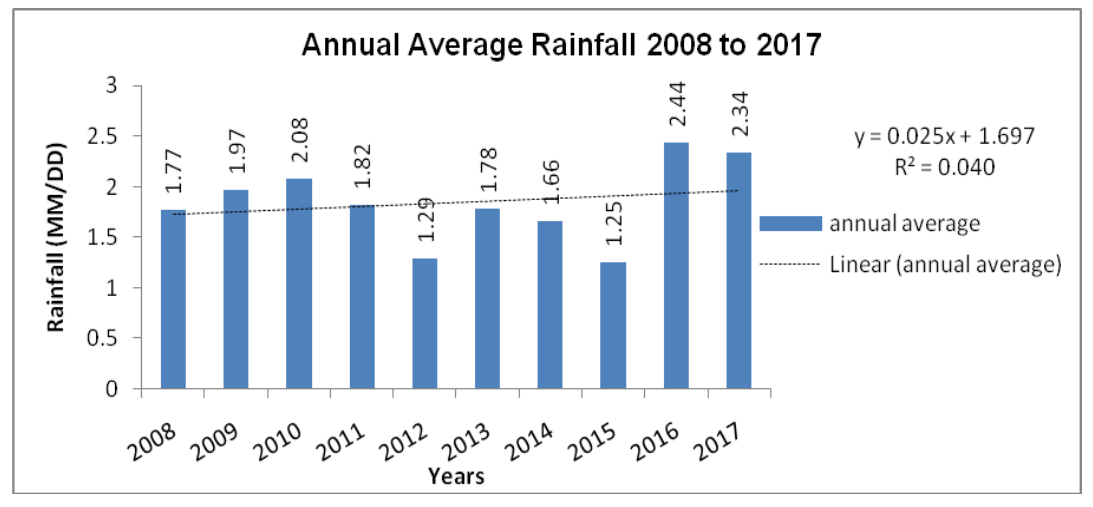

Chart.2 Annual average temperature from 2008 to 2017

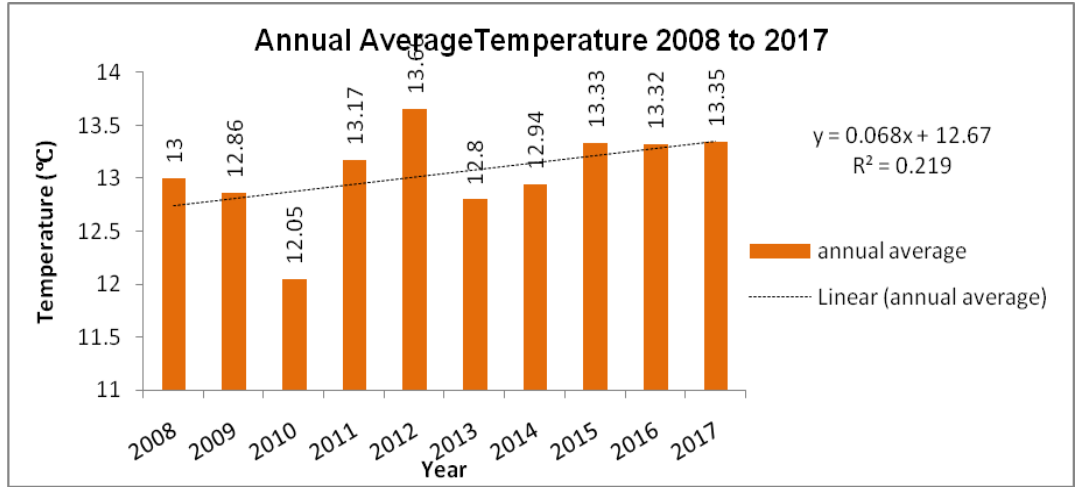

Chart.3 Annual average relative humidity from 2008 to 2017

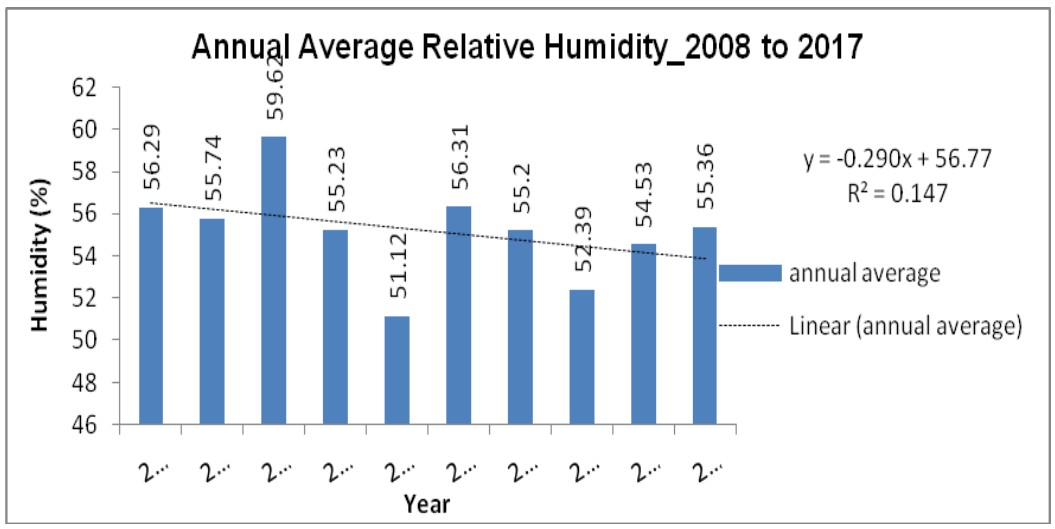

In conclusion, the outcomes of climate change increased temperature and rainfall, and reduced humidity which has lead to changes in grape crop. The changes in temperature, relative humidity, precipitation, have lead to the development of fungal disease. Environmental factors have significant influence on the biology and epidemiology of fungal infections of grapes. Disease severity changes according to the changes in temperature, Relative Humidity and rainfall. Fungal diseases of grapes are prevalent in almost all grape-growing areas of Tasgaon tehsil from moderate to severe extent. Precipitation needs to be considered in climate 
change studies as this is likely to directly and indirectly affect the distribution of tropical insect pest species. Meteorological factors are responsible for plant diseases (Rumbidzai et al., 2017).

\section{Acknowledgement}

I would like to thank our Director, Dr. Erach Bharucha and our Principle Dr. Shamita Kumar and our Prof. Dr. Kranti Yardi for giving the opportunity to study on this project.

\section{References}

Anand Prakash, Jagadiswari Rao, Arup K. Mukherjee J. Berliner Somnath S. Pokhare Totan Adak Sushmita Munda P.R. Shashank (2014): Climate Change: Impact on Crop Pests.

David R. Just, Holly Ameden (2001): Pests and Agricultural Production under Climate Change. Department of Agricultural and Resource Economics University of California, Berkeley American Agricultural Economics Association Annual Meetings Chicago, August 2001. Pp.1-25.

Laxmikantha, Malini, Gouda (2018): "Impacts of Climate Change on Agriculture Sector using RS and GIS." International Research Journal of Engineering and Technology (IRJET). 05: 940-945.

Ghosh Debjit Chaitali Chakraborty and Riya Dasgupta (2017): A Survey on Indian Grapes at Sangli, Maharashtra, India. International Journal of Current Microbiology and Applied Sciences. vol: 6 Number 5 (2017) pp. 1904-1911

Intergovernmental Panel on Climate Change (IPCC). (2013). Working group III,
Mitigation of Climate Change (Chapter 1, pp. 3-4). IPCC, Geneva.

Johnson, S. N., Mitchell, C., McNicol, J. W., Thompson, J., and Karley, A. J. (2013): Downstairs drivers--root herbivores shape communities of aboveground herbivores and natural enemies via changes in plant nutrients. The Journal of Animal Ecology, 82(5), 10211030.

Maoela A. Malebajoa (2010): Climate Change Impacts on Crop Yields and Adaptive Measures for Agricultural Sector in the Lowlands of Lesotho. Department of Physical Geography and Ecosystem Analysis Lund University.

Patil, A. B. (2008): A study on constraint analysis of grape exporting farmers of Maharashtra state (PhD Thesis). UAS, Dharwad.

Parvatha Reddy, P. (2013): Impact of climate change on insect pests, pathogens and nematodes. Pest Management in Horticulture Ecosystems, vol 19(2). Pp. 225-233

Rumbidzai D. Katsaruware-Chapoto, Paramu L. Mafongoya and Augustine Gubba (2017): Responses of Insect Pests and Plant Diseases to Changing and Variable Climate: A Review. Vol. 9, No. 12.

Sluys, S.L. (2006): Climatic Influences on the Grapevine: A Study of Viticulture in the Waipara Basin. University of Canterbury.

Karuppaiah, V. and G.K. Sujayanad (2012): Impact of Climate Change on Population Dynamics of Insect Pests. World Journal of Agriculture Sciences. 8(3): 240-246.

Prasad, Y. G. and O. M. Bambawale (2010): Effects of Climate Change on Natural Control of Insect Pests. Indian J. Dryland Agric. 25(2): 1-12.

\section{How to cite this article:}

Patil Tejashri and Yardi Kranti. 2019. Impact of Changing Weather Conditions on the Disease Pattern on Grapes in Tasgaon Tehsil in Maharashtra, India. Int.J.Curr.Microbiol.App.Sci. 8(05): 1395-1402. doi: https://doi.org/10.20546/ijcmas.2019.805.159 